(Final version to appear in Kantian Review)

\title{
Kant's (Non-Question-Begging) Refutation of Cartesian Scepticism
}

\author{
Colin Marshall (University of Washington, Seattle)
}

\begin{abstract}
Interpreters of Kant's Refutation of Idealism face a dilemma: it seems to either beg the question against the Cartesian sceptic or else offer a disappointingly Berkeleyan conclusion. In this paper I offer an interpretation of the Refutation on which it does not beg the question against the Cartesian sceptic. After defending a principle about questionbegging, I identify four premises concerning our representations that there are textual reasons to think Kant might be implicitly assuming. Using those assumptions, I offer a reconstruction of Kant's Refutation that avoids the interpretive dilemma, though difficult questions about the argument remain.
\end{abstract}

It is hard not to feel disappointed by Kant's Refutation of Idealism. Against

Descartes' sceptical doubts about the external world, Kant promises us a demonstration that there is 'a thing outside me and not... [a] mere representation of a thing outside me' (B275). ${ }^{1}$ In so doing, Kant distances himself from Berkeley's idealism (B274), which takes objects to be mere representations. Yet Kant's one-paragraph argument has struck many readers as being woefully unsound unless its conclusion is Berkeleyan. We face an interpretive dilemma: either admitting that the argument begs the question against the sceptic or else accepting that its conclusion is Berkeleyan.

\footnotetext{
${ }^{1}$ All references to the first Critique will use the standard A/B format, with translations from Kant 1997. References to Kant's other works will be to volume and page number of the Academy edition (Kant 1900); translations: lectures on logic from Kant 1992; Prolegomena from Kant 2001. References to Descartes will be to volume and page number of Descartes 1984-91 (using the usual abbreviation 'CSM').
} 
Some solutions have been offered to this dilemma, but none have found widespread acceptance. ${ }^{2}$ My aim in this paper is to defend a new interpretation of the Refutation that (i) does not beg any questions against the Cartesian sceptic and (ii) concludes by positing spatial objects with a genuine mind-independent existence. That said, my interpretation is not a full defence of the Refutation - in particular, I do not defend all of Kant's premises. My interpretation is also not philosophical magic. It would take such magic, I believe, to prove the existence of a robustly mind-independent world merely on the basis of indubitable, first-personal states. My interpretation can therefore, at best, assuage only some feelings of disappointment. But if I am right, Kant did not attempt philosophical magic in the Refutation (he is an idealist of some sort), and magic is not needed to refute a genuine Cartesian sceptic.

A refutation (eine Widerlegung), in Kant's sense, need not change an opponent's mind. In the Jäsche Logic, Kant writes,

[the] disclosure and breaking up of illusion is a far greater service to truth... than the direct refutation of errors, whereby one does not block their source... [Someone who persists in an absurdity] has thereby made himself... incapable of further

\footnotetext{
${ }^{2}$ For one statement of the dilemma, see Allison 2004: 291, 298. The best-known attempted solution is that proposed in Guyer 1987 (developed in Dicker 2008, Dicker 2011 and criticized in Chignell 2010, Chignell 2011. Some interpreters deny that a Berkeleyan conclusion is problematic (e.g. Emundts 2010). Karl Ameriks denies that the Refutation is concerned with traditional scepticism at all (Ameriks 2003: 18). Nonetheless, Ameriks's larger reading is similar in spirit to my own (see Ameriks 2000: 115-20). There are also some similarities between my interpretation and Henry Allison's (Allison 2004: 285-303), but my reconstruction does not require Allison's particular understanding of Kant's idealism (see below).
} 
correction and refutation... ${ }^{3}$

I therefore take a successful Kantian refutation of Cartesian scepticism to be a sound, nonquestion-begging argument whose conclusion is inconsistent with Cartesian scepticism (though it may be compatible with other forms of scepticism). Such an argument should convince neutral, reasonable readers that scepticism is mistaken (cf. A423/B451), but need not sway committed sceptics. The reason not to beg the question against the sceptic is not to win her over, therefore, but rather to convince reasonable third parties that Cartesian scepticism is false.

My discussion begins by identifying the target of Kant's argument $(\S 1)$, before describing how the Refutation seems to beg the question $(\$ 2)$. I then offer a principle about when a premise does not beg the question (§3). Using that principle, I describe four Kantian assumptions that would not beg the question $(\S 4, \S 5, \S 6)$, and then give a nonquestion-begging, non-Berkeleyan reconstruction of the Refutation’s proof $(\S 7)$. Since question-begging is not the only vice an argument can have, I conclude by briefly discussing the overall merits of the argument, including the plausibility of its premises $(\S 8)$.

Three caveats. (I) My focus is on identifying implicit assumptions in the Refutation, ones that lighten the philosophical load that Kant's explicit assumptions need to carry. The implicit assumptions I attribute to Kant are ones that have been defended elsewhere in the literature. Nonetheless, they are exegetically and philosophically controversial, and I do not attempt a full interpretive or philosophical defence of them. One defence of some of the premises can be found in putatively charitable 'metaphysical one-

\footnotetext{
${ }^{3}$ Jäsche Logic 9:56
} 
world' readings of Kant's metaphysics. ${ }^{4}$ That said, the reconstruction I propose is compatible with some (but only some) other putatively charitable readings of Kant's metaphysics as well, such as Henry Allison's non-metaphysical reading. My interpretation does, however, posit quite a few non-trivial implicit assumptions (four, as I formulate them), and this makes it less parsimonious than some other interpretations - especially ones that allow the argument to be question-begging or invalid. ${ }^{5}$

(II) As Paul Guyer and others have emphasized, the Refutation has a rich history in Kant's Nachlass and in Kant's later thoughts on the topic. ${ }^{6}$ The interpretation I offer is, I think, supported by much of those other texts. Due to space limitations, however, I do not attempt to show that here.

(III) I follow Henry Allison in taking question-begging to be a particularly important worry about the Refutation. ${ }^{7}$ However, there are other difficult interpretive and philosophical issues that a complete defence of the Refutation would need to address. One issue is how the Refutation relates to Kant's Analogies of Experience. ${ }^{8}$ Another is how to understand Kant's talk of 'time determination' (Zeitbestimmung), which plays a central role in the demonstration. Yet another is what justification Kant can offer for his claims about the relations among our representations. ${ }^{9}$ My aim here, however, is only to show how the argument can achieve its non-Berkeleyan conclusion without begging the question

\footnotetext{
${ }^{4}$ See, e.g., Rosefeldt 2007, Ameriks 2011, Allais 2015.

${ }^{5}$ For one discussion of parsimony vs. interpretive charity, see Cohn and Keyt 1992.

${ }^{6}$ See Guyer 1987, Part IV. But cf. Bader 2012.

${ }^{7}$ See, in particular, Allison 2004: 291.

${ }^{8}$ Guyer argues that there are challenges in reconciling the Refutation with Kant's Analogies and with his idealism (Guyer 1998: 319-23). For another type of worry, see Vogel 1993. I touch on both issues below.

${ }^{9}$ For a recent discussion of this, and of Kant's other explicit premises, see Bader 2017.
} 
against the Cartesian sceptic. Showing this, I hope, will provide guidance on other interpretive questions and bring us closer to a complete defence of the Refutation.

\section{Kant's target: the Cartesian sceptic}

Kant tells us who the specific target of the Refutation is: 'the theory that declares the existence of objects in space outside us to be... merely doubtful... [This] is the problematic idealism of Descartes, who declares only one empirical assertion, namely I am, to be indubitable' (B274). ${ }^{10}$ Kant apparently takes the narrator of the Meditations to be describing Descartes' own views. Since that may be a mistake, I describe Kant's argumentative opponent as the Cartesian meditator or the Cartesian sceptic. Many types of scepticism have been dubbed 'Cartesian', so we should clarify what Kant has in mind. B274 provides two points of guidance. First: the entities whose existence is in question are 'objects in space,' not mind-independent objects in general. Kant repeats this in stating the theorem to be proved: 'The mere, but empirically determined, consciousness of my own existence proves the existence of objects in space outside me' (B275, see also Bxxxixn). Kant never suggests that the Refutation is concerned with sceptics who doubt the existence of everything outside their mind.

Second: Kant states that the Cartesian sceptic allows only one indubitable empirical assertion, namely, 'I am.' ${ }^{11}$ This leaves open the possibility that the Cartesian sceptic accepts some non-empirical assertions. In the first note to the Refutation, Kant gives one

\footnotetext{
${ }^{10}$ Kant also mentions Berkeley's idealism in this passage, but states that 'this idealism, however, has [already] been undercut by us in the Transcendental Aesthetic' (B274).

${ }^{11}$ On 'I am' being empirical, see B152-59 and B422-23n.
} 
example: '[i]dealism assumed that the only immediate experience is inner experience' (B276). Presumably, Kant therefore thinks that which experiences are immediate is not an empirical issue for the Cartesian sceptic. ${ }^{12}$

These considerations show which part of Descartes' Meditations Kant is focused on. By the end of the Meditations, Descartes' narrator no longer doubts spatial objects' existence and makes many empirical assertions. So Kant's conception of problematic idealism is based on Meditations I and II. There, the narrator focuses his doubts on the existence of spatial objects, though the doubts also extend to God. The culmination of the doubts is expressed as follows:

Anything which admits of the slightest doubt I will set aside... [So] everything I see is spurious... Body, shape, extension, movement and place are chimeras... Is there not a God, or whatever I may call him, who puts into me the thoughts I am now having? But why do I think this, since I myself may perhaps be the author of these thoughts? In that case am not I, at least, something? ${ }^{13}$

This, I claim, is the specific form of Cartesian scepticism Kant is concerned with: the doubting of the existence of spatial things. We can now consider how well the Refutation fares against its target.

\footnotetext{
${ }^{12}$ Or he may think this is an empirical but dubitable claim. What matters for my purposes is that Kant allows the sceptic to accept non-empirical claims.

${ }^{13}$ CSM II: 16. In this passage, the meditator also supposes that 'my memory tells me lies'. Nothing in the Refutation shows that Kant was concerned with memory scepticism, but my interpretation below requires only perceptions as of something persisting.
} 


\section{How Kant's argument seems to beg the question}

Here is the core text of the Refutation, with the amendment Kant suggests at Bxxxixn. added in brackets:

Theorem: The mere, but empirically determined, consciousness of my own existence proves the existence of objects in space outside me. Proof: I am conscious of my existence as determined in time. All time-determination presupposes something persistent in perception. [This persistent thing, however, cannot be an intuition in me. For all grounds of determination of my existence that can be encountered in me are representations, and as such require something persistent that is distinct even from them, in relation to which their change, thus my existence in the time in which they change, can be determined.] Thus the perception of this persistent thing is possible only through a thing outside me and not through the mere representation of a thing outside me. Consequently, the determination of my existence in time is possible only by means of the existence of actual things that I perceive outside myself. // Now consciousness in time is necessarily combined with the consciousness of the possibility of this time-determination: Therefore it is also necessarily combined with the existence of the things outside me, as the condition of time-determination; i.e., the consciousness of my own existence is at the same time an immediate consciousness of the existence of other things outside me. (B275-76)

Kant's proof is naturally divided into two parts, marked here with a double slash. 
The first half is primarily metaphysical, concluding with "the existence of actual things that I perceive outside myself'. The second half is more epistemological, concluding that 'the consciousness of my own existence is at the same time an immediate consciousness of the existence of other things outside me'. Like other commentators, I focus on defending the first half, even if Kant's ultimate aim is achieved only in the second. ${ }^{14}$

From its first step on, Kant's proof raises difficult questions. Even the relation of the first premise to the Theorem is obscure. What exactly are 'determinations' in this context? Is 'consciousness of my existence as determined in time' supposed to be equivalent to '[t]he mere, but empirically determined, consciousness of my own existence'? Most of the questions the proof raises do not directly bear on whether it begs the question against the Cartesian sceptic, however, since that sceptic is not particularly concerned with issues like the temporal determination of consciousness. The main question that does directly bear on that issue is the following. The proof seems to begin with only one ontological commitment, namely, a commitment to my (temporallydetermined) existence. The proof ends, however, with an ontological commitment to 'actual things that I perceive outside myself'. Given what Kant has told us beforehand, we know that 'outside' is meant spatially. Hence, the conclusion posits the very things whose existence the Cartesian sceptic denies. Yet it is hard to see how any valid argument could start with just the former ontological commitment and end with the latter, unless it begged the question at some point. We can easily imagine the grim scenario Mark Twain describes:

\footnotetext{
${ }^{14}$ E.g. Emundts 2010: 168, who does not mention the second half of the proof. The 'proves' ('beweiset') in the Theorem may be intended to imply that the subject herself is conscious of outer things in being conscious of her own existence. This epistemological conclusion is also anti-Cartesian; the subtitle of the Second Mediation is 'The nature of the human mind, and how it is better known than the body' (CSM II: 16).
} 
[T]here is no God, no universe, no human race, no earthly life, no heaven, no hell. It is all a dream - a grotesque and foolish dream. Nothing exists but you. And you are but a thought—a vagrant thought, a useless thought, a homeless thought, wandering forlorn among the empty eternities! $!^{15}$

Proving that such a scenario is impossible would seem to require philosophical magic.

If Kant's proof contains such magic, it is hard to find. The proof appeals to 'something persistent in perception,' which can be read as being either a real temporal thing or a mere perception as of a temporal thing. The perception of that persisting thing is said to be possible 'only through a thing outside me and not through the mere representation of a thing outside me'. Kant says little about how this is supposed to work. Some commentators have suggested that Kant is drawing on the Analogies of Experience here (A176/B218-A218/B265), ${ }^{16}$ but the Analogies do not have any obvious antiCartesian magic either. It is therefore hard to see how Kant's proof can reach its ontologically-robust conclusion from its ontologically-modest premise without begging the question against its target. ${ }^{17}$

Hence, some commentators have concluded that Kant's conclusion takes spatial objects to be mere representations, despite his claim that he is concerned with 'a thing outside me,' and not 'the mere representation of a thing outside me'. The Cartesian

\footnotetext{
${ }^{15}$ Twain 1992: 121.

${ }^{16}$ E.g. Abela 2002: 186.

${ }^{17}$ Luigi Caranti claims: 'Even if we accept the transcendental apparatus on which the Refutation turns, all we can assume without begging the question is that the subject 'take' this permanent as a real object... But this task can be accomplished by a mere illusion' (Caranti 2007: 149).
} 
sceptic accepts that we have representations of spatial objects, after all. This would bring Kant's view close to Berkeley's, however, which he explicitly rejects in the introduction to the Refutation. Of course, Kant could be either misunderstanding or misrepresenting Berkeley's view. It would be desirable, however, if we could find a non-Berkeleyan reading of Kant's argument that did not beg the question against its target. My approach will be to identify implicit premises we can attribute to Kant that involve an additional (but dialectically safe) ontological commitment. Before doing so, however, I turn to the general question of when an argument begs the question.

\section{Question-begging}

Some philosophers see question-begging as a pragmatic phenomenon, such as a violation of conversational rules. ${ }^{18}$ Others see it as purely epistemic, such as using a premise one could justifiably accept only if one already had a justified belief in the conclusion. ${ }^{19}$ Partly for these reasons, it is often hard to evaluate whether a given argument is question-begging. ${ }^{20}$

Question-begging comes in both relational and non-relational forms. An argument can beg the question against a particular thinker, or it can beg the question simpliciter.

\footnotetext{
${ }^{18}$ E.g. Walton 1994.

${ }^{19}$ E.g. Sgaravatti 2013. Sgaravatti and others take begging the question to be the same fallacy as circular argument (petitio principii). One reason for denying that is that question-begging can be relative to a target, but not so argumentative circularity.

${ }^{20}$ See, e.g., Fischer and Pendergraft 2013.
} 
These may or may not be inter-definable. ${ }^{21}$ My concern here is only with sufficient conditions for avoiding relational question-begging at the level of individual premises. I propose the following disjunctive principle:

No Begging: A premise $\mathrm{P}$ does not beg the question against a thinker $\mathrm{T}$ if (a) $\mathrm{T}$ explicitly or implicitly accepts $\mathrm{P}$ or if (b) $\mathrm{P}$ crucially involves notions that $\mathrm{T}$ never considers and $\mathrm{P}$ alone does not conflict with anything $\mathrm{T}$ accepts.

Let's consider each disjunct separately.

On (a): if I accept $\mathrm{P}$, and you appeal to $\mathrm{P}$ in arguing against me, then I should not complain that you are begging the question against me. That holds even if your argument exploits an inconsistency in my views. If I have asserted both $\mathrm{P}$ and not-P while denying $\mathrm{Q}$, then there is nothing question-begging about you appealing to $\mathrm{P}$ in $\operatorname{arguing}$ for $\mathrm{Q}$ against me.

On (b): consider Kant's assumption, in his arguments-by-elimination against transcendental realists, that space and time might be forms of intuition. ${ }^{22}$ That assumption crucially involves the notion of a form of intuition. By 'crucially involves,' I mean that the

\footnotetext{
${ }^{21}$ If the below principle is correct, the argument ' $\mathrm{P}$, therefore $\mathrm{P}$ ' is not question-begging against someone who both accepts and denies $\mathrm{P}$, though it is a clear case of begging the question simpliciter. More tentatively, the argument, 'P, therefore $\mathrm{P}$ or $(\mathrm{Q}$ or not-Q)' might not be question-begging simpliciter, but might beg the question against someone who denied P. I therefore suspect there is no inter-definition for relational and nonrelational question-begging (contra Fischer and Pendergraft 2013: 581).

${ }^{22}$ E.g., at A39-41/B56-58, Prolegomena 4:282.
} 
premise could not contribute to the argument if it were reformulated without that notion. ${ }^{23}$ Kant's assumption about forms of intuition does not beg the question against the transcendental realists because the realists Kant is concerned with never considered this notion and because the assumption itself does not conflict with transcendental realism. ${ }^{24}$ For those reasons, Kant's assumption does not seem question-begging against the realists. This is what disjunct (b) of No Begging is meant to capture.

No Begging applies only to individual premises. However, some arguments, as a whole, beg the question even though no individual premise does. Consider, for example, an argument of the form (directed at someone who denies $\mathrm{P}$ ): $\mathrm{P}$ or $\mathrm{R}, \mathrm{P}$ or not- $\mathrm{R}$, therefore $\mathrm{P} .{ }^{25}$ Because it focuses on individual premises, No Begging does not tell us why such arguments are question-begging. Fortunately, my purposes do not require any general principle. Instead, I take a two-step intuitive approach: to determine whether Kant's argument is question-begging, we(1) clear its individual premises using No Begging, and then (2) make an intuitive holistic assessment of whether the premises in combination beg the question against the relevant thinker (e.g., via logical tricks).

\footnotetext{
${ }^{23}$ Consider, for example: 'If I am thinking, I have neuronal synapses; if I have neuronal synapses, something physical exists; therefore...' Descartes never considers the notion of a neuronal synapse. But, intuitively, these premises do not crucially involve that notion - the argument is really just about appealing to some or other part of the brain.

${ }^{24}$ Lack of conflict is not enough to avoid question-begging. Consider the premise, "if something has doubts, then it has a brain and exists among spatial objects.' That premise alone does not conflict with a Cartesian sceptic's commitments, but still seems question-begging. This is partly because the only way one could justify this premise would be via arguments that did beg the question against the sceptic. The premises I invoke below are ones that Kant either thinks do not need further justification or thinks can be justified without question-begging against the Cartesian sceptic.

${ }^{25}$ Sgaravatti 2013: 4.
} 


\section{Implicit assumption: Affection}

I now turn to identifying assumptions that (i) would not beg the question against the Cartesian sceptic and that (ii) we have textual reasons to ascribe to Kant. This section presents one assumption, and $\S 5-6$ present three more. In $\S 7$, I argue that these assumptions can make the Refutation valid without begging the question against the Cartesian sceptic. In $\S 8$, I briefly consider how plausible these assumptions are.

The first assumption is:

Affection: All perceptions result from the mind being affected by some object that exists independently of them. ${ }^{26}$

This assumption could be formulated in terms of 'cognitions' or 'experiences.' Perception, however, is Kant's focus in the Refutation. Kant consistently describes perceptions (Wahrnehmungen) as involving sensation (Empfindung) ${ }^{27}$ Whatever else perceptions may involve, Kant thinks sensations arise through affection. Kant endorses Affection in various places. For instance:

There is no doubt whatever that all our cognition begins with experience; for

\footnotetext{
${ }^{26}$ Perception-independence can be understood either modally (being able to exist without perceptions) and non-modally (not existing in virtue of perceptions).

${ }^{27}$ B147 describes perceptions as 'representations accompanied with sensation'. See also A115, B207, Proleg. 4:300, Met. Vigilantius 29:999, Met. Mrongrovius 29:794. Kant sometimes identifies perception with empirical intuition (e.g. Anthropology 7:135, 7:153 and Prolegomena 4:283). See Tolley Forthcoming.
} 
how else should the cognitive faculty be awakened into exercise if not through objects that stimulate our senses and... produce representations...? (B1, cf. Proleg. 4:275)

Similarly, Kant defines sensation in the Transcendental Aesthetic, as ' $[\mathrm{t}] \mathrm{he}$ effect of an object on the capacity for representation, insofar as we are affected by it' (A19-20/B34). The natural reading of these passages takes the object affecting the mind to have a perception-independent existence. That natural reading has been rejected by some commentators. ${ }^{28} \mathrm{I}$ do not enter into that debate here, though I think a larger consideration of Kant's views supports the natural reading. ${ }^{29}$

Granting the natural reading, Kant's confidence about Affection is striking. J. N. Findlay writes that, for Kant, Affection is 'a primordial certainty which stands in no need of justification, even if its lack of empirical content means that it can never be ranked as knowledge ${ }^{30}$ Findlay implies that Kant regards Affection as non-empirical. This is what we should expect, if Affection concerns what happens prior to the most basic elements of experience (sensations and perceptions). Against Findlay's suggestion that it is 'primordial' for Kant, though, we might think Affection has a priori grounds, such as the principle that objects can change only by being affected by other objects (a principle Kant accepts in some pre-Critical work). ${ }^{31}$ Or we might think that Affection is part of the

\footnotetext{
${ }^{28}$ E.g. Kitcher 1999.

${ }^{29}$ For two defences of the natural reading, see Hogan 2009 and Stang 2015.

${ }^{30}$ Findlay 1981: 2 .

${ }^{31}$ Kant argues for this in the 1755 Nova Dilucidatio. See Watkins 2005: Chapter 2.
} 
concept of experience, arising through mere analysis. ${ }^{32}$ In any case, Kant regarded it as non-empirical. He therefore could rely on Affection while holding that the Cartesian sceptic only granted one empirical claim ('I am').

Note that Affection does not say that perceptions represent the affecting objects that helped produce them. It is compatible with the perceptions being pure hallucinations that do not represent anything real. At the same time, Affection does not rule out the view that perceptions represent their causes (as, e.g., Spinoza thought) - a view that Descartes himself might have accepted. ${ }^{33}$ I return to this issue in $\S 6$.

On my interpretation, Affection is key to avoiding the ontological leap I described in §2. Would Affection beg the question against the Cartesian sceptic? Affection says nothing about the nature of the objects that affect us. It does not say they are spatial. Nor does it say whether the affecting object might be us or something in us. For this reason, Kant could use Affection in an anti-Cartesian argument without begging the question. For while Descartes' meditator doubts whether his experiences arise from spatial objects, he never considers whether they might come from nowhere. ${ }^{34}$ As we saw in $\S 1$, the most

\footnotetext{
${ }^{32}$ Alternatively, we might claim we come to appreciate its truth through a special sort of reflection. See Westphal 2004: 52-55.

${ }^{33}$ See Axiom 4 of Part 1 of the Ethics. In the Sixth Meditation and the Passions, Descartes does seem to accept that perceptions represent (albeit confusedly) the objects that gave rise to them (CSM II: 55; CSM I: 335). Importantly, none of the sceptical claims in the first two Meditations are incompatible with this view of intentionality, though it would imply that, oddly, a deceiving demon who produced a perception of paper was itself the object of that perception (i.e., the demon was misperceived as being paper). So Kant probably could have employed a stronger version of Affection that did posit a causal-representational connection. Thanks to a referee for $K R$ for discussion of this point.

${ }^{34}$ This could be because of a principle stated in Meditation III: 'there must be as much reality in the efficient and total cause as in the effect of that cause' (CSM II: 28).
} 
radical alternatives the meditator considers are that his thoughts come from 'God, or whatever I may call him', or from himself. This was so despite the meditator's aim of doubting everything that could be doubted. The Cartesian sceptic therefore seems to implicitly agree with Kant that there is 'no doubt whatever' that Affection is true. If so, then No Begging allows Kant to use Affection without begging the question against his target.

\section{Implicit assumptions: Spatial and temporal perceptions}

The second and third implicit assumptions I ascribe to Kant are:

Perceived Time: If (a) an object affects the mind and produces sensations involved in a perception as of a (temporally) persisting object and (b) that perception coheres with the criteria of experience then (c) that affecting object is or constitutes a real, perceived persisting object. $^{35}$

Perceived Space: If (a) an object affects the mind and produces sensations involved in a perception as of a spatial object and (b) that perception coheres with the criteria of experience then (c) that affecting object is or constitutes a real object in space.

There is more than one way to motivate attributing these claims to Kant, but my approach starts with a certain metaphysical reading of Kant's idealism.

\footnotetext{
${ }^{35}$ The last 'perceived' here helps simplify my interpretation of Kant's proof below, but does not carry any real philosophical weight.
} 
On the reading in question, Kant holds that each object of experience is, in some important sense, the same thing as some mind-independent thing in itself. ${ }^{36}$ This sameness holds despite only the former entities being spatiotemporal. In contrast to some nonmetaphysical one-world readings, this reading holds that the appearance/thing in itself distinction is a distinction between properties of things, as opposed to merely between ways of representing things. On this view (unlike Berkeley's idealism), spatiotemporal properties are mind-dependent but belong to objects that have some kind of mindindependent existence. ${ }^{37}$ The properties are not mere representations, but are instead rooted in both the mind-independent objects and in the minds. This puts them halfway between purely mind-dependent properties and purely mind-independent properties. ${ }^{38} \mathrm{An}$ object's spatiotemporality consists in being perceived (or perceivable) as spatiotemporal, in virtue of that object affecting the mind in a certain way. Suitably elaborated, this type of idealism would imply Perceived Time and Perceived Space.

What are the criteria of experience that the two premises evoke? There is no easy summary of Kant's theory of the conditions of experience. But these conditions clearly concern the unity of experience, something Kant devotes far more attention to than his predecessors. Hence, Kant writes that,

experience rests on the synthetic unity of appearances, i.e., on a synthesis according to concepts of the object of appearances in general, without which it would not even be cognition but rather a rhapsody of perceptions, which would

\footnotetext{
${ }^{36}$ For two recent defenses, see Marshall 2013 and McDaniel 2015.

${ }^{37}$ However, on one version of this reading (Rosefeldt 2007), spatiotemporal properties are pure dispositions of objects, which are mind-independent in a quite strong sense.

${ }^{38}$ For this way of locating Kant's idealism, see Ameriks 2011: 31.
} 
not fit together in any context in accordance with rules of a thoroughly connected (possible) consciousness (A156/B195)

Kant's criteria of experience hinge on the idea of a synthetically unified consciousness. Kant suggests that this unity of consciousness is the keystone to the whole of his transcendental philosophy (B134n.).

The relevance of this to the Refutation is clear from Note 3 to the Refutation, where Kant writes, '[w]hether this or that putative experience is not mere imagination must be ascertained according to its particular determinations and through its coherence with the criteria of all experience' (B279). On the reading of Kant's idealism I have been discussing, it is when and only when we properly connect (or could properly connect) our perceptions that an object that is perceived as having some spatiotemporal property really has that property. What this 'proper connection' ultimately amounts to is one of the central interpretative questions about the Critique. For now, it is enough to think of it as some relation among representations that Kant thinks his predecessors have overlooked.

So interpreted, Kant sees spatiotemporal qualities as complex secondary qualities of objects. As Kant knew, Descartes never contemplated the possibility that space or time might be secondary qualities. In the Prolegomena, Kant describes the 'generally accepted' view of warmth and color as predicates that "belong not to these things in themselves but only to their appearances'. Kant then claims that his view differs from this only insofar as he says the same thing about 'extension, place, and more generally space' (4:289). Of course, the nature of secondary qualities is controversial (and Kant's readers have understood it in various ways ${ }^{39}$ ). What matters here is that there are ways of understanding

\footnotetext{
${ }^{39}$ Cf. Allais 2007 and Rosefeldt 2007.
} 
Kant's claims about secondary qualities that support attributing Perceived Time and Perceived Space to him.

There is at least one other way to motivate attributing these premises to Kant. These claims are compatible with certain forms of realism about spatiotemporal properties. A realist could take Perceived Time and Perceived Space as merely stating a sufficient condition for accurate perceptions of temporal and/or spatial objects. The criteria of experience would then be playing a purely epistemological role. Perceived Time and Perceived Space would then hold because the relevant conditions are those under which spatiotemporal perceptions are veridical. Some of Kant's readers, such as Henry Allison, have thought that Kant's 'idealism' should be understood along these lines, as an unobjectionable realism combined with subtle non-metaphysical claims about epistemic conditions. ${ }^{40}$

Readings like Allison's are less popular now than they once were. ${ }^{41}$ The important point, however, is that Perceived Time and Perceived Space are neutral about the metaphysical status of time and space. Hence, my reconstruction of the Refutation below does not hinge on the above metaphysical interpretation of Kant's idealism (though it may not be compatible with all readings of Kant's idealism). I now turn to showing how, according to the second disjunct of No Begging, neither Perceived Time nor Perceived Space begs the question against the Cartesian sceptic.

First, the Cartesian sceptic never considers Kant's notion of a criterion of

\footnotetext{
${ }^{40}$ Allison claims that the Refutation of Idealism presupposes transcendental idealism (Allison 2004: 300). A broadly Allisonian approach to the Refutation is further developed in Caranti 2007. By contrast, Kenneth Westphal claims that Kant's non-idealist views contain resources for a promising anti-sceptical argument (see esp. Westphal 2004: 250-61).

${ }^{41}$ For noteworthy criticisms, see Van Cleve 1999 and Allais 2015.
} 
experience, which both Perceived Time and Perceived Space crucially involve. To be sure, in Meditation VI, the meditator claims that coherence can distinguish dreams from waking life. ${ }^{42}$ This, however, makes no appeal to anything like the synthetic unity of consciousness, which Kant sees as essential to the criteria of experience. Nor does the meditator consider the possibility of space and time being secondary qualities, or of Allisonian non-metaphysical epistemic conditions.

Second, the two premises do not directly conflict with anything the Cartesian sceptic accepts. By themselves, they are consistent with the non-existence and unknowability of the material world and of God. They do not imply that we even have perceptions as of spatiotemporal objects or that any perceptions we do have meet the criteria of experience. That does not mean that a Cartesian sceptic would simply accept them, of course. Seeing where the argument was headed, a determined sceptic might challenge the notion of a criterion of experience. Even so, according to the second disjunct of No Begging, the claims can be used in a refutation (in Kant's sense) without begging the question against the Cartesian sceptic. Whether that argument could itself change any determined sceptic's mind is another question.

Two further notes. First: In the introduction to the Refutation, Kant states that the view of space 'as a property that is to pertain to the things in themselves' has been 'undercut by us in the Transcendental Aesthetic' (B274). Kant therefore had his own views about space and time firmly in mind as he wrote the Refutation. It would not be surprising, therefore, if the Refutation implicitly appealed to that view, such as by assuming Perceived Time and Perceived Space.

Second: Unlike Affection, Kant probably has background arguments in support

\footnotetext{
${ }^{42}$ CSM II: 61-62.
} 
of Perceived Time and Perceived Space (primarily in the Transcendental Aesthetic). Therefore, even Perceived Time and Perceived Space alone would somehow beg the question against the Cartesian sceptic, Kant may have further arguments for them that would not. ${ }^{43}$ In that case, the combined argument of the Refutation together with the Aesthetic's arguments would not beg the question against the Cartesian.

\section{Minimal Coherence and Intentionality}

Neither by themselves nor in conjunction with Kant's explicit premises do Affection and Perceived Time/Space imply that our perceptions represent any real object (accurately or otherwise), or that there are any real spatiotemporal objects. Hence, my reconstruction requires one further implicit assumption:

Minimal Coherence: (a) If there is at least one perception as of a persisting thing, then there is at least one perception that is as of a persisting thing and coheres with the criteria of all experience. (b) If there is at least one perception as of a spatial thing, then there is at least one perception that is as of a spatial thing and coheres with the criteria of all experience.

In effect, this says that if there are any temporal and spatial perceptions, at least some of these perceptions meet the relevant criteria.

\footnotetext{
${ }^{43}$ Do the arguments of the Aesthetic beg the question against the Cartesian sceptic (e.g., by assuming the applicability of geometry to objects)? The division between the metaphysical and transcendental expositions in the Aesthetic (see B37-42) makes it harder to raise this worry for the Critique than for the Prolegomena (see, 4:281-83).
} 
Minimal Coherence may be hinted at in Note 3 after the Refutation, where Kant casually grants that any particular perception may be 'the mere effect of the imagination (in dreams as well as in delusions)' (B278). Here is one way to motivate the assumption within Kant's framework. If Kant's criteria concern unity, then they should pick out the most unified perceptions. That is, whichever perceptions hold together best satisfy Kant's criteria. ${ }^{44}$ That would explain why Kant states that '[in] space and time... the empirical truth of appearances is satisfactorily secured, and sufficiently distinguished from its kinship with dreams, if both are correctly and thoroughly connected up according to empirical laws in one experience' (A492/B520-21). Provided that there are spatiotemporal perceptions, Kant seems confident that at least some must satisfy the criteria of all experience. ${ }^{45}$ As a rough gloss: given any set of perceptions, at least some of them can be woven together into a coherent course of experience (while the others are given the status of dreams or hallucinations). Note that this requires some actual perception, in accordance with the second Postulate (A218/B266, A225/B372), to which the Refutation is attached.

Though it could be challenged, ${ }^{46}$ Minimal Coherence would not beg the question

\footnotetext{
${ }^{44}$ Kant takes coherence to be substantial and causal: our perceptions must be as of causally-connected substances (see, e.g., B225, B236). However, the Cartesian meditator explicitly grants that he has perceptions as of substances (like hands) doing causal things (like holding paper).

${ }^{45}$ Kant may also have deeper grounds for expecting coherence (see A100-2).

${ }^{46}$ Minimal Coherence might fail in at least two ways. First, there could be a non-finite ascending series of perceptions (or possible perceptions), each of which precludes the perceptions below it from satisfying the criteria. Second, every perception could be in a jointly-disqualifying 'tie' with some other perception (or possible perception). I am not sure whether Kant can conclusively rule out such possibilities. It might be enough for his purposes, though, if Minimal Coherence is independently plausible (if not apodictically
} 
against the Cartesian sceptic. It again crucially involves the notion of criteria of experience, which the sceptic never considers, and it does not directly conflict with any claims that sceptic makes. Moreover, the Cartesian meditator's description of his experience of sitting by the fire sounds coherent (see CSM II, 13), and that sceptic never raises the possibility that there is not even a minimally coherent set of perceptions (though other sceptics might).

We can now return to an issue raised in $\S 4$ : what does it take for a perception $\mathrm{P}$ (as of something spatiotemporal) to represent some actual object $\mathrm{O}$ ? The premises I have offered imply a sufficient condition: if $\mathrm{O}$ produces $\mathrm{P}$ through affecting the mind, and $\mathrm{P}$ coheres with the criteria of experience, then $\mathrm{P}$ represents $\mathrm{O}$ (and, moreover, does so accurately, as spatiotemporal). For example, if a perception as of a square was produced by some mind-independent thing, and that perception coheres with the criteria of experience, then that perception accurately represents that mind-independent thing as being square (or, at least, having some spatial quality or other ${ }^{47}$ ).

Setting aside questions about spatiotemporal qualities, why would production plus the criteria be enough for an intentional relation between a perception and an object? Since this is a mere sufficiency claim, it could be motivated in more than one way. It would

necessary). Either way, the Cartesian sceptic gives no reason for believing in such an ascending series or ubiquitous disqualifying ties.

${ }^{47}$ Strictly speaking, all Kant's Refutation requires is at least one object with one spatial quality - that quality need not be represented in any perception. Accordingly, the theorem Kant claims to prove only posits 'the existence of objects in space outside me' (B275), which leaves open that the things we perceive have different spatial qualities than the ones we perceive them as having. Kant is therefore not, in the Refutation, attempting to answer a sceptic who challenges us to show that we have any accurate spatial perceptions (though cf. the A492/B520-21 passage quoted above). 
follow from a simple causal view like Spinoza's, on which whatever produces a perception is represented by it, though perhaps only confusedly (a view which, as noted above, Descartes himself might have accepted ${ }^{48}$ ). If the criteria of experience have modal implications, then the sufficient condition might also be supported by tracking accounts of intentionality. ${ }^{49}$ Finally, if the criteria have intersubjective implications, ${ }^{50}$ then the sufficiency condition might be supported by interpretationist theories of intentionality like Donald Davidson's. ${ }^{51}$ Kant may not have held any of these views, of course. The important point is that the view of intentionality implied by the above premises could be motivated in various ways - and motivated, moreover, without begging the question against the Cartesian sceptic.

\section{Reconstructing the Refutation}

There is more than one way to use the assumptions given above to reconstruct Kant's proof in the Refutation. Here is one such reconstruction:

1. I am aware of my existence as determined in time.

2. Any awareness of existence as determined in time requires a perception as of something persisting.

3. Therefore, there is at least one perception as of something persisting. $(1,2)$

4. Affection: All perceptions result from the mind being affected by some object that

\footnotetext{
${ }^{48}$ See also Ayers 1991 on Locke. Cf. A92/B124-25.

${ }^{49}$ For one contemporary version, see Tye 1995: 101.

${ }^{50}$ As suggested, e.g., at Prolegomena 4:298.

${ }^{51}$ Davidson 1984.
} 
exists independently of them.

5. Minimal Coherence: (a) If there is at least one perception as of a persisting thing, then there is at least one perception that is as of a persisting thing and coheres with the criteria of all experience. (b) If there is at least one perception as of a spatial thing, then there is at least one perception that is as of a spatial thing and coheres with the criteria of all experience.

6. Perceived Time: If (a) an object affects the mind and produces sensations involved in a perception as of a persisting object and (b) that perception coheres with the criteria of experience then (c) that affecting object is or constitutes a real, perceived persisting object.

7. Therefore, there is at least one real, perceived persisting object. $(3,4,5 a, 6)$

8. If there is at least one real, perceived persisting object, then there is at least one perception as of a spatial object.

9. Therefore, there is at least one perception as of a spatial object. $(7,8)$

10. Perceived Space: If (a) an object affects the mind and produces sensations involved in a perception as of a spatial object and (b) that perception coheres with the criteria of experience then (c) that affecting object is or constitutes a real object in space.

11. Therefore, there is at least one real object in space. $(4,5 b, 9,10)^{52}$

Bracket the question of whether the premises are philosophically plausible (the

\footnotetext{
${ }^{52}$ Jonathan Vogel worries that the Refutation requires, but cannot show, that the persisting thing be something other than the self (Vogel 1993). My reconstruction leaves open that the self might be the persisting thing. Nonetheless, Vogel's worry gets at a deeper issue, which I return to below.
} 
topic of $\S 8$, and consider how this fares as an interpretively plausible, non-questionbegging reconstruction of Kant's proof. On an interpretive level, there is straightforward textual motivation for ascribing premises 1,2 , and 8 to Kant. ${ }^{53}$ Though these premises involve significant philosophical complexities, none of them would beg the question against the Cartesian sceptic. The Cartesian sceptic accepts 1, and has no independent reason to deny 2 or 8 . Given No Begging, none of the other assumptions $(4,5,6,10)$ would beg the question against the Cartesian sceptic either. The individual premises are therefore cleared of the change of question-begging against Kant's target. In accordance with my suggestion in $\S 3$, we should now make an intuitive holistic assessment of whether the premises beg the question in combination. Intuitively, I claim, there is no holistic problem here. Unlike the case mentioned above (P or R, P or not-R, therefore $\mathrm{P}$ ), this reconstruction does not involve a question-begging structural trick. The reconstruction therefore does not beg the question against the Cartesian sceptic.

Issues of interpretive plausibility and question-begging aside, the reconstruction has other desired features. It is logically valid, and its conclusion is not Berkeleyan. Though the conclusion is consistent with counting spatiality as a secondary quality, it does not construe the object as mere representations. Nor does it require identifying spatial properties with mere representations. This reconstruction therefore avoids the interpretive dilemma I described in the introduction.

So interpreted, the argument has two significant limitations. First: It does not

\footnotetext{
${ }^{53}$ As far as interpretation goes, the most potentially controversial premise is 8 . Nonetheless, 8 resembles some of Kant's earlier claims (e.g. 'the representations of outer sense make up the proper material with which we occupy our mind' (B67)). Though Kant posits a real persisting thing in the argument, an alternative reconstruction could instead use the premise that if there is a perception as of a persisting thing, then there is a perception as of a spatial thing (bypassing the need for Perceived Time).
} 
establish that spatial objects exist in the way that Descartes thought they did. Descartes thought spatial qualities were primary qualities of objects, and made no appeal to criteria of experience. In Kant's terms, he was a transcendental realist. Moreover, Descartes holds that only an appeal to God's existence can show that spatial objects exist. ${ }^{54}$ So Descartes might not have regarded the argument as a satisfactory answer to scepticism. Nonetheless, Kant aims to refute the Cartesian sceptic, not the actual Descartes. This sceptic, in the first two Meditations, takes no stand on whether spatial qualities are secondary. He does, in Meditation I, suggest that simple, general geometrical qualities are 'real,' and that geometry contains something 'indubitable'. ${ }^{55}$ These statements are neutral about the primary vs. secondary metaphysical status of space, however (cf. B41, B70-71).

Second: The argument leaves open what the spatial object is in itself, that is, what the thing is that affects the mind and gives rise to spatial perceptions. The object could be something with primary spatial qualities, an all-powerful evil genius, God, or some unknown part of ourselves. This last possibility is especially disappointing if we were hoping Kant's Refutation would rule out the frightening Twainian scenario. Unfortunately, Kant seems open to something like this possibility. He grants that we can affect ourselves (see, e.g., B67-68), and insists on our ignorance about whether we differ in ourselves from outer things in themselves (see A379-80, B409, B427-28). This is the main reason I do not claim that my reconstruction would assuage all feelings of disappointment. Yet we should remember that all Kant explicitly promised in the Refutation was a proof of the existence of real things in space. Given his idealism, that conclusion leaves open whether, at some deeper level, we are all alone.

\footnotetext{
${ }^{54}$ E.g., CSM II: 55.

${ }^{55}$ CSM II: 14.
} 
That said, Kant may have further resources for lessening our disappointment. First of all, Kant's confidence that thought must have a deeper ground shows that he would reject the Twainian possibility of the self being a lonely thought. That is a consequence of Affection, which requires some perception-independent entity. Second, Kant never says that $I$ might be the ground of outer appearances, and he denies that this ground is a thinking being in itself (A379-80). Given our limited knowledge about things in themselves, why is Kant so confident about this?

The answer, I suspect, is that Kant has an account of the self that makes it impossible for the self to be identical to any thing in itself. Elsewhere, I have argued that, for Kant, the self is a thing or things insofar as that thing or things perform acts of judgement and synthesis that unify some course of experience (by analogy, a fist is a hand insofar as it is clenched). ${ }^{56}$ Say, then, that there is a single thing that gives rise to our perceptions and to our unifying thoughts/syntheses. That thing is not the self, nor is the self that thing insofar as it gives rise to mere perceptions, even though all of these entities metaphysically overlap (in the way that my hand, fist, and open hand metaphysically overlap). Given this account, then, the self cannot be completely alone. This is a broadly Spinozist view: the self is not a fundamental entity, but instead shares an ultimate ground with other things. To be sure, if we're looking for metaphysically non-overlapping company, we will still be disappointed with this conclusion. ${ }^{57}$ But Spinozism is very

\footnotetext{
${ }^{56}$ Marshall 2010. These acts of unification involve, for Kant, relations among perceptions, and so fall outside the realm of things in themselves.

${ }^{57}$ The mature Kant never allows that self-affection could produce all our representations. Matters are less clear for the Cartesian sceptic. Though he considers that 'I myself may perhaps be the author of these thoughts' (CSM II, 16), this is less than his being the source of all his spatiotemporal perceptions. So perhaps the Refutation can be strengthened via a stronger construal of Affection.
} 
different from solipsism.

The above non-Cartesian account of the self would not beg the question against the Cartesian sceptic since the sceptic never considers this kind of insofar-as metaphysical construction. Descartes himself would have rejected this account, though, and we might reasonably ask whether Kant has arguments for his account that would not beg the question against Descartes. For now, though, the point is that Kant may have further grounds for denying that we are all alone.

\section{Further merits of the argument}

Kant's proof, so reconstructed, has several philosophical virtues. It is valid, it does not beg the question against the Cartesian sceptic, and its conclusion is not Berkeleyan. Nevertheless, a bad argument could have all these virtues. In this section, I focus on two further evaluative topics: the complex structure of the argument and the plausibility of its crucial premises.

The argument has a structural vice: it could easily be shorter. It could have instead started with the claim that we have at least one perception as of a spatial thing. Together with Affection, Minimal Coherence, and Perceived Space, that would yield the desired conclusion. Moreover, assuming at least one perception as of a spatial object would not beg the question against the Cartesian sceptic, since the sceptic accepts as much in the Meditations. If my reconstruction is right, then, why did Kant not give a shorter argument?

One thing to say is that Kant seems proud of the fact that his argument requires only one empirical assertion, namely, that I am. The assertion that we have at least one spatial perception would also be empirical, by his lights. So Kant seems to think that 
refuting the Cartesian sceptic requires not making empirical assumptions about spatial perceptions. This may be because the perception of spatial objects is not as central to Meditations I and II as awareness of temporally-determined thinking is. Moreover, the argument is more philosophically impressive if its only empirical premise is about something that is not even perceived as spatial. So there are virtues to the longer argument, even if a shorter argument would have worked.

The next question is the plausibility of the argument's premises. A complete defence of the Refutation would have to fully justify all its premises. My aim now is more modest: to show that the above premises have at least some plausibility. Premise 1 (that I am aware of my existence as determined in time) seems safe enough, provided the notion of determination is understood in some straightforward way. For reasons explained above, Minimal Coherence also seems fairly plausible, though that hinges on what criteria of experience are supposed to be. That leaves us with Premises 2 and 8, along with Affection, Perceived Time, and Perceived Space.

Premise 2 states that any awareness of existence as determined in time requires a perception as of something persisting. Premise 8 states if there is at least one real, perceived persisting object, then there is at least one perception as of a spatial object. Both claims are hard to assess. At a minimum, though, they are consistent with ordinary experience. We typically do have perceptions as of something persisting and perceptions as of something spatial (e.g., the feeling of our own bodies). Moreover, it is hard to imagine experience without such perceptions. Consider Guyer's case of images with 'digital timers in their corners,' presented as a counterexample to Kant's claim that time determination requires spatial objects. Such a digital timer in our representations would still be a 
representation as of a persisting, spatial thing. ${ }^{58}$ Getting a clear counterexample to these premises requires stretching our philosophical imagination further, towards a scenario where we are aware only of the temporal order of our thoughts. ${ }^{59}$ Such far-flung thought experiments are hard to assess, and this shows that Premises 2 and 8 have at least some plausibility. That said, it is far from obvious how one would establish their truth. ${ }^{60}$ If my argument so far has been successful, then perhaps the most daunting challenge in providing a complete defence of the Refutation would be justifying these premises (though they would need to carry less weight on my reconstruction than on some others).

The next premise to consider is Affection. I have left open whether Kant has deeper reasons for accepting this claim. Kant's own beliefs aside, it is hard to see how to prove Affection. Nonetheless, Affection has some intuitive plausibility. Consider how much easier it is to motivate scepticism with brain-in-vat scenarios than with a scenario in which perceptions a-causally come to be. Even radical idealists like Berkeley accepted Affection. Of course, an argument using Affection would beg the question against the most radical sceptics - but Kant those sceptics are not Kant's target.

Above, I suggested that Perceived Time and Perceived Space can be motivated by a complex secondary-quality view of spatiotemporal qualities. Unlike Affection, this view is probably not part of common sense. However, the secondary-quality view can be understood as a view about some spatiotemporal qualities. We seem to perceive space as three-dimensional, and time as involving absolute simultaneity relations. Post-Newtonian

\footnotetext{
${ }^{58}$ Guyer 1987, 244. See also Chignell 2009: 499-500. Matters get trickier if Minimal Coherence requires that the relevant perceptions be as of something substantial and causally connected. Even so, a perception as of a digital timer might still be a perception as of something substantial and causally connected.

${ }^{59}$ See Anscombe 1994.

${ }^{60}$ See Marshall 2014 for my preferred understanding of Kant's methodology.
} 
physics gives us reasons to think that other spatiotemporal qualities are primary, such as 11-dimensional space or time as involving only relativistic simultaneity. Perceived Time and Perceived Space do not imply that all spatiotemporal properties are perceivable, despite what Kant thought (see, e.g., A42/B59). If so, then the secondary quality view might be the closest we can come to saving the commonsense view of familiar spatiotemporal qualities. ${ }^{61}$

I therefore claim that all of the premises have at least some plausibility. Still, for all I have said, Kant's argument might be unsound. In that case, he would not have refuted the Cartesian sceptic. Nonetheless, if the premises are sufficiently plausible, then we have reason to think that the Refutation is successful until shown otherwise.

There are further questions that could be raised about my reconstruction, including how it compares to other interpretations and whether it remains too idealistfriendly. I hope to have shown, though, that the argument has significant virtues. While, disappointingly, it cannot defeat all forms of scepticism, it may refute the best-known form of scepticism in modern philosophy, and that would be a significant achievement on Kant's part. ${ }^{62}$

\footnotetext{
${ }^{61}$ Cf. Sellars 1968.

${ }^{62}$ Thanks to Ralf Bader, Ann Baker, Larry Bonjour, Jonny Cottrell, Dai Heide, Pat Kitcher, Jessica Leech, Samantha Matherne, James Messina, Tristram Oliver-Skuse, Mike Raven, Nick Stang, participants in the 2014 North American Kant Society Pacific meeting, members of Jonny Cottrell's Fall 2015 Kant course at Wayne State, and two referees for Kantian Review.
} 


\section{Works Cited}

Abela, Paul. (2002) Kant's Empirical Realism. Oxford: Oxford University Press.

Allais, Lucy. (2015) Manifest Reality: Kant's Idealism and his Realism. Oxford: Oxford University Press.

--(2007) 'Kant's Idealism and the Secondary Quality Analogy'. Journal of the History of Philosophy 45, 459-84.

Allison, Henry. (2004) Kant's Transcendental Idealism, $2^{\text {nd }}$ edition. New Haven: Yale University Press.

Ameriks, Karl. (2011) 'Kant's Idealism on a Moderate Interpretation'. In Schulting and Verburgt (eds.), Kant's Idealism: New Interpretations of a Controversial Doctrine.

Dordrecht: Springer, 29-53.

--(2003) Interpreting Kant's Critiques. Oxford: Oxford University Press.

--(2000) Kant's Theory of Mind, $2^{\text {nd }}$ edition. Oxford: Oxford University Press.

Anscombe, G.E.M. (1994) 'The First Person'. In Quassim Cassam (ed.), Self-Knowledge. Oxford: Oxford University Press, 140-59. 
Ayers, Michael. (1991) Locke: Epistemology and ontology, 2 vols. London: Routledge.

Bader, Ralf M. (2017) ‘The Refutation of Idealism'. In James R. O’Shea (ed.), Kant's 'Critique of Pure Reason': - A Critical Guide. Cambridge University Press, 205-22.

--(2012) 'The Role of Kant's Refutation of Idealism'. Archiv für Geschichte der Philosophie 94, 53-73.

Caranti, Luigi. (2007) Kant and the Scandal of Philosophy: The Kantian Critique of Cartesian Scepticism. Toronto, Buffalo and London: University of Toronto Press.

Chignell, Andrew (2011). 'Causal Refutations of Idealism Revisited'. Philosophical Quarterly 61 (242): 184-86.

--(2010). 'Causal Refutations of Idealism'. Philosophical Quarterly 60, 487-507.

Cohen, S. Marc and Keyt, David. (1992) ‘Analysing Plato’s Arguments: Plato and Platonism'. In James Klagge and Nicholas Smith (eds.), Oxford Studies in Ancient Philosophy; Supplementary Volume: Methods of Interpreting Plato and His Dialogues. Oxford: Clarendon Press.

Davidson, Donald. (1984) Inquiries into Truth and Interpretation. Oxford: Clarendon.

Descartes, Rene. (1984-91) Philosophical Writings of Descartes, 3 vols. Trans. John 
Cottingham, Robert Stoothoff, Dugald Murdoch, and Anthony Kenny. Cambridge:

Cambridge University Press.

Dicker, Georges (2011) 'Kant's Refutation of Idealism: A Reply to Chignell’. Philosophical Quarterly 61, 175-83.

--(2008) 'Kant's Refutation of Idealism'. Noûs 42, 80-108.

Emundts, Dina. (2010) 'The Refutation of Idealism and the Distinction between Phenomena and Noumena' In Paul Guyer (ed.), Cambridge Companion to Kant's Critique of Pure Reason. Cambridge: Cambridge University Press, 168-89.

Findlay, J. N. (1981) Kant and the Transcendental Object. Oxford: Clarendon Press.

Fischer, John Martin and Pendergraft, Garrett. (2013) 'Does the consequence argument beg the question?' Philosophical Studies 166, 575-95.

Guyer, Paul. (1998) 'The Postulates of Empirical Thinking in General and the Refutation of Idealism'. In G. Mohr and M. Willaschek (eds.), Kritik der reinen Vernunft. Berlin: Akademie Verlag.

--(1987) Kant and the Claims of Knowledge. Cambridge: Cambridge University Press.

Hogan, Desmond. (2009) 'Noumenal Affection'. Philosophical Review 118, 501-32. 
Kant, Immanuel (1900-) Kants Gesammelte Schriften. Ed. German Academy of Sciences. Berlin: De Gruyter.

--(1992) Lectures on Logic. Trans. J. Michael Young. Cambridge: Cambridge University Press.

--(1997) Critique of Pure Reason. Trans. Paul Guyer and Allen Wood. Cambridge:

Cambridge University Press.

--(2001) Prolegomena to Any Future Metaphysics. Trans. Gary Hatfield. Cambridge: Cambridge University Press.

Kitcher, Patricia. (1999) 'Kant's Epistemological Problem and its Coherent Solution’. Philosophical Perspectives 13, 415-41.

Marshall, Colin. (2014) 'Does Kant Demand Explanations for All Synthetic A Priori Claims?' Journal of the History of Philosophy 52, 549-76.

--(2013) 'Kant's Appearances and Things in Themselves as Qua-Objects'. Philosophical Quarterly 63, 520-45.

--(2010) 'Kant's Metaphysics of the Self'. Philosophers' Imprint 10, 1-21 
McDaniel, Kris. (2015) 'A Philosophical Model of the Relation Between Things in Themselves and Appearances'. Nô̂s 49, 643-64.

Rosefeldt, Tobias. (2007) 'Dinge an sich und sekundäre Qualitäten'. In J. Stolzenburg (ed.), Kant in der Gegenwart. Berlin and New York: Walter de Gruyter, 167-209.

Sellars, Wilfred. (1968) Science and Metaphysics: Variations on Kantian Themes. London: Routledge and Kegan Paul.

Sgaravatti, Daniele. (2013) 'Petitio Principii: A Bad Form of Reasoning'. Mind 122, 74979.

Spinoza, Baruch (1988) The Collected Works of Spinoza, vol. 1. Ed. and trans. Edwin Curley. Princeton: Princeton University Press.

Stang, Nick. (2015) 'Who's Afraid of Double Affection?' Philosophers' Imprint 15, 1-28.

Tolley, Clinton. (Forthcoming) 'The Meaning of 'Perception' in Kant and his Historical Context'. Proceedings of the 12th International Kant Congress.

Twain, Mark. (1992) The Mysterious Stranger and Other Stories. New York: Dover.

Tye, Michael. (1995) Ten Problems of Consciousness: A Representational Theory of the 
Phenomenal Mind. Cambridge, MA: MIT Press.

Van Cleve, James. (1999) Problems from Kant. Oxford: Oxford University Press.

Vogel, Jonathan. (1993) 'The Problem of Self-Knowledge in Kant's "Refutation of Idealism": Two Recent Views'. Philosophy and Phenomenological Research 53, 875-87.

Walton, Douglas (1994) 'Begging the Question as a Pragmatic Fallacy'. Synthese 100, 95131.

Watkins, Eric. (2005) Kant and the Metaphysics of Causality. New York: Cambridge University Press.

Westphal, Kenneth R. (2004) Kant's Transcendental Proof of Realism. New York: Cambridge University Press. 